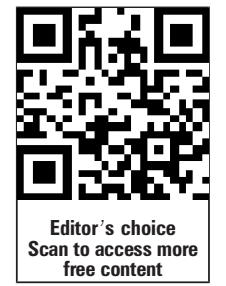

${ }^{1}$ Research and Strategy, Ambulance Victoria, Melbourne, Australia

${ }^{2}$ Department of Epidemiology and Preventive Medicine,

Monash University, Melbourne, Australia

${ }^{3}$ Alfred Hospital, Melbourne, Australia

\section{Correspondence to} Dr Conor Deasy, Monash University, Department of Epidemiology and Preventive Medicine, Alfred Hospital, Level 5 Alfred Centre, 99 Commercial Road, Melbourne 3004 Australia;

conordeasy@hotmail.com

Accepted 13 June 2012

Published Online First

4 July 2012

\title{
Functional outcomes and quality of life of young adults who survive out-of-hospital cardiac arrest
}

\author{
Conor Deasy, ${ }^{1,2,3}$ Janet Bray, ${ }^{1}$ Karen Smith, ${ }^{1,2}$ Linton Harriss, ${ }^{2}$ Stephen Bernard, ${ }^{1,2,3}$ \\ Peter Cameron, ${ }^{2,3}$ on behalf of the VACAR Steering Committee
}

\section{ABSTRACT}

Background Evaluating the quality of life of young adult survivors of out-of-hospital cardiac arrest (OHCA) is important as they are likely to have a longer life expectancy than older patients. The aim of this study was to assess their functional and quality of life outcomes.

Methodology The Victorian Ambulance Cardiac Arrest Registry records were used to identify survivors of OHCA that occurred between 2003 and 2008 in the 18-39 yearold age group. Survivors were administered a telephone questionnaire using Short Form (SF-12), EQ-5D and Glasgow Outcome Scale-Extended. Cerebral Performance Category (CPC) ascertained at hospital discharge from the medical record was recorded for the uncontactable survivors.

Results 0 the 106 young adult survivors, five died in the intervening years and 45 were not contactable or refused. CPC scores were obtained for 37 (74\%) of those who did not take part in telephone follow-up, and $7(19 \%)$ of these had a CPC $\geq 3$ indicating severe cerebral disability. The median follow-up time was 5 years (range 2.7- 8.6 years) for the 56 (53\%) patients included. Of these, $84 \%$ were living at home independently, 68\% had returned to work, and only $11 \%$ reported marked or severe disability. The majority of patients had no problems with mobility $(75 \%)$, personal care $(75 \%)$, usual activities $(66 \%)$ or pain/ discomfort $(71 \%)$. However, $61 \%$ of respondents reported either moderate $(48 \%)$ or severe $(13 \%)$ anxiety.

Conclusions The majority of survivors have good functional and quality of life outcomes. Telephone follow-up is feasible in the young adult survivors of cardiac arrest; loss to follow-up is common.

\section{INTRODUCTION}

Cardiopulmonary resuscitation has the aim of returning patients to independent living. Therefore, although survival at hospital discharge is a key measure of resuscitation success, intact functional status may be more important. Health-related quality of life refers to the physical, psychological and social aspects of health as seen in domains that are influenced by a person's experiences, beliefs, expectations and perceptions. ${ }^{1}{ }^{2}$ Previous studies have reported that half of survivors of out-ofhospital cardiac arrest (OHCA) have permanent brain damage of varying degrees. ${ }^{3} 4$ However, a recent systematic review of quality of life after cardiac arrest found studies reported good quality of life after cardiac arrest survival. ${ }^{5}$
There is remarkable heterogeneity of methodology among studies assessing functional and/or quality of life in cardiac arrest survivors and there is no consensus regarding the preferred tools or the best timing of assessment. ${ }^{5}$ The Cerebral Performance Category (CPC) score, ${ }^{6}$ though not well validated, has been recommended as part of the Utstein guidelines for reporting cardiac arrest outcomes ${ }^{7}$ and is widely used by investigators. ${ }^{67} \mathrm{It}$ is designed to indicate overall functional status of cardiac arrest survivors but does not measure differences among survivors who have high cerebral function $^{8}$ or their quality of life. It has the advantage of being simple to use and a score at hospital discharge can usually be ascertained from the hospital records.

Young adults represent a minority of those who suffer an OHCA. ${ }^{9}$ The functional and quality of life outcomes in this group are particularly important as they are likely to have a longer life expectancy than older patients who sustain OHCA. Also, the aetiology of cardiac arrest may be different in young adults. For example, overdose associated OHCA features are more frequent than ischaemic heart disease as seen in older age groups. ${ }^{9}{ }^{10}$ On the other hand, there are challenges associated with following up this age group who often change contact details, are more mobile and may be less facilitative of follow-up. Previous publications have not focused on functional and quality of life outcomes in this age group. This paper describes the functional and quality of life outcomes in young adults who survive OHCA.

\section{METHODS \\ Patients}

Survivors of all OHCAs aged 18-39years and attended by Ambulance Victoria in metropolitan Melbourne between 1 January 2003 and 31 December 2008 were included.

\section{Setting}

Melbourne is the capital city of the state of Victoria in Australia. At the time of the last census (2006), Melbourne's population was 3.59 million, of whom 1.19 million were aged between 18 and 39 years of age with an equal male to female distribution. ${ }^{11}$

\section{Emergency medical services}

In Melbourne, the Advanced Medical Priority Dispatch System ${ }^{\odot}$ is used to receive emergency calls and Ambulance Victoria is the sole provider of emergency medical services (EMS). The EMS comprises ambulance paramedics who have some 
advanced life support skills (laryngeal mask airway, intravenous epinephrine) and mobile intensive care ambulance paramedics who are authorised to perform endotracheal intubation and administer a wider range of cardiac drugs. Mobile intensive care ambulance paramedics are dispatched to patients with critical illness, including patients with cardiac arrest. In addition, firefighter first-responders are dispatched to patients with suspected cardiac arrest in the inner two-thirds of Melbourne. ${ }^{12}$ The prehospital cardiac arrest protocols follow the recommendations of the Australian Resuscitation Council. ${ }^{13} 14$ Ambulance Victoria paramedics are not obliged to commence resuscitation when the presenting features are inconsistent with resuscitation. This includes decapitation, presence of rigour mortis, decomposition or postmortem lividity, where death has been declared by a Medical Officer who is or has been at the scene and where the presenting rhythm was monitored as asystole for $>30 \mathrm{~s}$, and there has been $>10$ min downtime with no evidence of hypothermia, drug overdose or family/bystander objections. Paramedics may discontinue resuscitation in the field if advanced life support has been performed for $30 \mathrm{~min}$ without return of spontaneous circulation, the rhythm is not ventricular fibrillation or ventricular tachycardia, there are no signs of life, no gasps or evidence of pupillary reaction and no evidence of hypothermia or drug overdose. ${ }^{13}$

\section{Victoria Ambulance Cardiac Arrest Registry}

The Victoria Ambulance Cardiac Arrest Registry (VACAR) is a population-based registry containing Utstein and additional outcome data for all EMS attended OHCAs occurring in the Australian state of Victoria since 1999. ${ }^{15}$ Paramedics attending OHCA enter clinical data into a laptop computer at the conclusion of the case. The VACAR data are extracted from this electronic patient record into a purpose built database. Data collection is standardised and quality controlled. Survival to hospital discharge in VACAR is obtained from all treating hospitals $(n \sim 100)$. Since January 2011, VACAR has prospectively collected functional and quality of life outcomes data at 12-months postarrest.

For the purpose of this study, retrospective QOL data were captured for young adult patients who had OHCA from 2003 to 2008. Hospital investigation results were not recorded in VACAR for the time period involved in this study. EMS response time is the time from emergency call to EMS arrival at scene. VACAR was used to identify young adults aged between 18 through 39 years who had sustained OHCAs between 2003 and 2008 and who had been discharged alive from hospital.

\section{Ethics approval and consent}

VACAR has been classified as a quality assurance project by the ethics committee at the Department of Health. The collection of cardiac arrest outcome data by VACAR was approved by the ethics committees of all Victorian hospitals receiving cardiac arrests by ambulance. This study was approved by Monash University's Human Research Ethics Committee. Young adult survivors were sent a letter approximately 1 month in advance of receiving the telephone follow-up in which the reason for the study was explained. An option was offered to opt-out of the study and telephone, email and postal contact details were included.

\section{Instruments}

We adopted the functional and quality of life outcomes assessment tools used by the Victorian State Trauma Registry; these are administered by telephone. ${ }^{16}$ None of the instruments selected require specific qualifications, certification or training by the instrument supplier or by the copyright holder. The full patient interview includes the following data collection:

1. Prearrest demographics, including the highest level of education achieved, occupation and employment status.

2. Work-related disability, including whether the patient returned to the same employer and the same role.

3. Residential or living status and whether additional support services are required.

4. Glasgow Outcome Scale-Extended (GOS-E) which provides a global measure of function on a scale from death to upper good recovery. Important domains such as self-care, mobility in the community, return to work, relationships, social activities and leisure activities are considered. ${ }^{17}$ Global measures of disability were recorded in the week before the 5 OHCA and in the week of the telephone interview are recorded.

5. The EQ-5D which is a self-reporting questionnaire validated to measure the quality of life in health-related research ${ }^{19} 20$ has been found to correlate with Short Form 36 (SF-36) and Health Utility Index version 3 scores in a variety of populations. ${ }^{21} 22$ In addition, this may be used to calculate 'quality adjusted life years' and has been used in general critical illness survivors ${ }^{23} 24$ and cardiac arrest outcomes reporting. $^{25} 26$

6. The Short Form 12 (SF-12) provides a measure of the physical and mental health status and is used widely in the literature. It can be administered by telephone, is quick to administer and there are Australian population norms for comparison. The SF-12 encompasses eight domains: physical functioning, social functioning, mental health, role limitations due to physical problems, role limitations due to emotional problems, vitality (energy and fatigue), bodily pain and general health perceptions. While the more detailed SF-36 from which the SF-12 has been derived has been used previously in cardiac arrest outcomes reporting ${ }^{27-29}$ the SF-12 has not. A SF-12 Physical Component Summary Score or Mental Component Summary Score $\leq 40$ represents moderate to severe disability.

7. For cases where it was not possible to apply the telephone questionnaire, a CPC at hospital discharge was derived from the hospital chart. A CPC score of 1 was given if the patient is conscious, alert, able to work, though might have a mild neurological or psychological deficit. CPC 2 is given if there was moderate cerebral disability: the patient is conscious, has sufficient cerebral function for independent activities of daily life and able to work in a sheltered environment. CPC 3 describes severe cerebral disability: the patient is conscious and dependent on others for daily support because of impaired brain function; this ranges from an ambulatory state to severe dementia or paralysis. CPC 4 describes a patient who is comatose without the presence of brain death criteria. CPC 5 describes brain death, apnoea, areflexia, ECG silence, etc.

\section{Mode of administration of telephone interview}

For survivors at hospital discharge, the Victorian Registry of Births Deaths and Marriages was cross checked to ascertain whether the patient had died in the interim period. Ambulance accounts records, the Victorian telephone directory and the hospital medical record were used to establish the address and contact details for the patient. Four attempts, at different times of the day, were made to contact patients over a month-long period. The interviewer had clinical experience and could 
appreciate the clinical scenarios and issues, provide information about services and deal with the distressed or dissatisfied patient. An algorithm for dealing with the distressed participant was required for ethics committee approval. Interviews were performed from a central location, rather than from individual health services ensuring quality control, interviewer trouble shooting and debriefing.

\section{Statistical analysis}

All data were entered into an Access database (Version 2003, Microsoft, Redmond, Washington, USA). Statistical calculations were performed on STATA software (V.10.0 Stata Corporation). $\chi^{2}$ Analyses were used for categorical variables. Continuous variables were compared using the t test (normal distribution) or Mann-Whitney. We adjusted SF-12 for Australian norms and present results as mean with SD. Multivariate logistic regression analysis was performed to examine Utstein elements associated with good neurological outcome; a good neurological outcome was defined as CPC 1 or 2 or GOS-E $\geq 5$ and represents independent living.

\section{RESULTS}

During the study period, there were 2361 OHCAs in young adults of whom 928 (39\%) had an attempted EMS resuscitation,

Table 1 Characteristics of the 106 young adult OHCA survivors (18-39 years of age) in metropolitan Melbourne between 1 January 2003 and 31 December 2008

\begin{tabular}{|c|c|c|c|}
\hline $\begin{array}{l}\text { Patient and arrest } \\
\text { characteristics }\end{array}$ & $\begin{array}{l}\text { Overall } \\
(n=106 *)\end{array}$ & $\begin{array}{l}\text { Successful } \\
\text { telephone } \\
\text { Follow-up } \\
\text { group }(n=56)\end{array}$ & $\begin{array}{l}\text { CPC group } \\
(\mathrm{n}=37)\end{array}$ \\
\hline Age at time of arrest & $29(23-35)$ & $29(23-35)$ & $30(23-36)$ \\
\hline Age at time of follow-up & $35(29-41)$ & $35(29-41)$ & $36(29-41)$ \\
\hline Time to follow-up & $5(4-6)$ & $5(4-6)$ & $4.9(4-5)$ \\
\hline Male sex & $78(74)$ & $40(71)$ & $29(78)$ \\
\hline \multicolumn{4}{|l|}{ Location of $\mathrm{OHCA}$} \\
\hline Home & $58(55)$ & $33(59)$ & $17(46)$ \\
\hline Work & $7(7)$ & $4(7)$ & $3(8)$ \\
\hline Street/public place & $24(23)$ & $11(20)$ & $9(24)$ \\
\hline In ambulance & $3(3)$ & $3(5)$ & $0(0)$ \\
\hline Sports venue & $6(6)$ & $4(7)$ & $2(5)$ \\
\hline Other & $8(7)$ & $1(2)$ & $6(16)$ \\
\hline \multicolumn{4}{|l|}{ Precipitant to $\mathrm{OHCA}$} \\
\hline Presumed cardiac & $60(57)$ & $36(64)$ & $20(54)$ \\
\hline Trauma & $9(8)$ & $2(4)$ & $5(13)$ \\
\hline Respiratory & $9(8)$ & $7(12)$ & $1(3)$ \\
\hline Overdose & $20(19)$ & $6(11)$ & $10(27)$ \\
\hline Drowning & $1(1)$ & $1(2)$ & 0 \\
\hline Hanging & $5(5)$ & $2(4)$ & $1(3)$ \\
\hline Electrocution & $1(1)$ & $1(2)$ & 0 \\
\hline Sepsis & $1(1)$ & $1(2)$ & 0 \\
\hline No witness & $32(30)$ & $11(20)$ & $13(35)$ \\
\hline Lay witnessed & $54(51)$ & $35(62)$ & $15(41)$ \\
\hline EMS witnessed & $20(19)$ & $10(18)$ & $9(24)$ \\
\hline Bystander CPR & $42(40)$ & $25(45)$ & $13(35)$ \\
\hline \multicolumn{4}{|l|}{ Rhythm } \\
\hline Ventricular & $55(52)$ & $35(62)$ & $15(40)$ \\
\hline Fibrillation & $14(13)$ & $3(5)$ & 7 (19) \\
\hline Asystole & $17(16)$ & $8(14)$ & $6(16)$ \\
\hline Pulse Electrical Activity & $20(19)$ & $10(18)$ & $9(24)$ \\
\hline
\end{tabular}

*Includes those who were not traceable $(n=7)$, died $(n=5)$, CPC not possible from chart information $(\mathrm{n}=1)$.

$\mathrm{CPC}$, Cerebral Performance Category; EMS, emergency medical services; OHCA, out-ofhospital cardiac arrest; CPR, cardiopulmonary resuscitation.

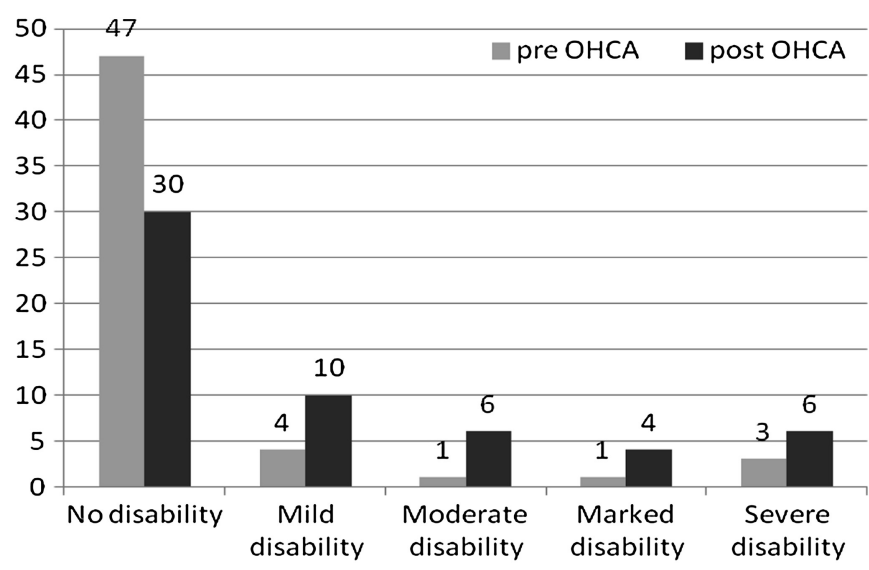

Figure 1 Global Outcome Assessment $(n=56)$. OHCA, out-of-hospital cardiac arrest.

and 106 (9\%) were alive at hospital discharge. When linked with the Victorian Registry of Births Deaths and Marriages, it was found that $5(5 \%)$ patients had died in the intervening time since discharge from hospital. Of the remaining 101 patients, 56 $(55 \%)$ were successfully contacted and undertook the telephone follow-up questionnaire. The family of two patients asked not to be contacted after the receipt of the information letter; however, they did not object to the hospital notes being used to ascertain the CPC. Both had poor functional outcomes. Three patients on being telephoned refused to take part in the telephone survey; they did not object to their CPC being ascertained from the hospital record. The CPC score was ascertained from the hospital records in 37 (37\%) patients. The CPC could not be determined from the hospital notes for one patient. Seven patients who could not be contacted also had hospital records that were unable to be examined. The median follow-up time was 5 years (range $2.7-8.6$ years).

Table 1 shows the characteristics of young adult survivors and the types of cardiac arrests they sustained. There were 14 patients with a presenting rhythm of asystole who survived to leave hospital; three patients had telephone follow-up, seven patients had their CPC ascertained from the chart and four patients were untraceable. Of these patients, eight were found to have a good outcome defined as CPC 1 or 2 or GOS-E $\geq 5$.

Figures 1 and 2 display the Global Outcome Assessment and Global Outcome Score-Extended for patients who underwent telephone follow-up. Figure 3 shows the CPC results for those patients not contactable by telephone. Overall, six of $56(11 \%)$ patients in the telephone follow-up group had a marked or severe disability while 7 (19\%) of the non-contactable group $(\mathrm{n}=37)$ had a CPC $>3$ on leaving hospital.

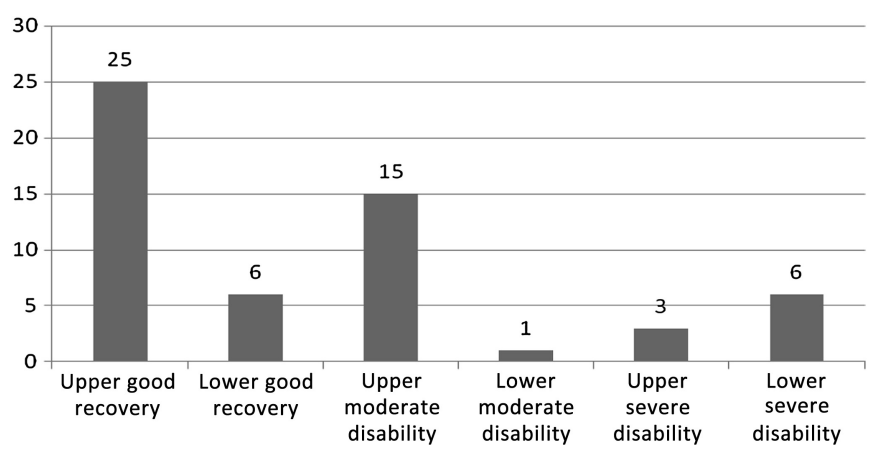

Figure 2 Global Outcome Score-Extended $(n=56)$. 


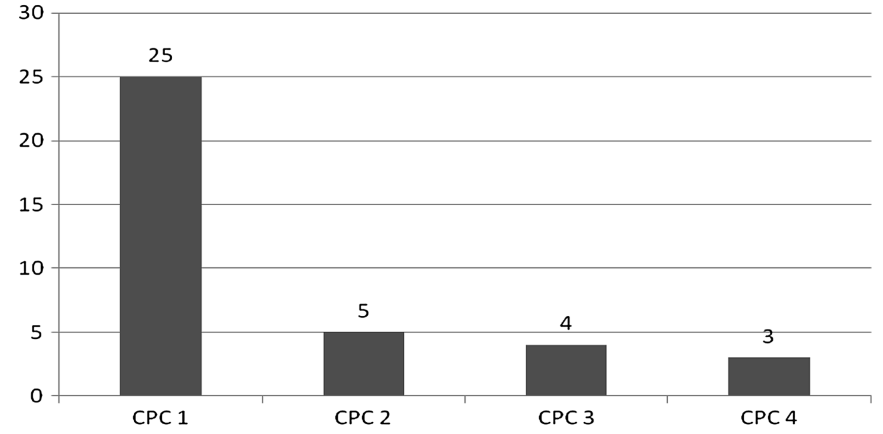

Figure 3 Cerebral Performance Category (CPC) score on patients not contactable by telephone $(n=37)$.

Table 2 details the demographics GOS-E and the EQ-5D results of the 56 patients who received telephone follow-up. Prior to their cardiac arrest, 47 (84\%) were working or studying; $32(68 \%)$ returned to work after their cardiac arrest, with 22

Table 2 Telephone follow-up successful $(n=56)$; demographics, Glasgow Outcome Score-Extended and EQ-5D results

\begin{tabular}{|c|c|}
\hline & $\mathbf{N}(\%)$ \\
\hline \multicolumn{2}{|l|}{ Occupation $(n=47)$} \\
\hline Student & $10(21)$ \\
\hline Other tradespersons & $4(8)$ \\
\hline Construction & $3(6)$ \\
\hline Immediate sales and related workers & $3(6)$ \\
\hline Business and administration associate professionals & $2(4)$ \\
\hline Business IT & $2(4)$ \\
\hline Other associate professionals & $2(4)$ \\
\hline Immediate service workers & $2(4)$ \\
\hline Intermediate plant operators & $2(4)$ \\
\hline Managing supervisors & $2(4)$ \\
\hline Associate professionals & $2(4)$ \\
\hline Other & $19(40)$ \\
\hline Returned to work after $\mathrm{OHCA}$ & $32(68)$ \\
\hline Returned to same role & $22(47)$ \\
\hline \multicolumn{2}{|l|}{ Education $(n=56)$} \\
\hline Advanced diploma, diploma or certificate & $17(30)$ \\
\hline Bachelor degree & $9(16)$ \\
\hline Did not go to school & $1(1)$ \\
\hline Other & $3(5)$ \\
\hline Postgraduate degree & $3(5)$ \\
\hline Year 12 or equivalent & $7(13)$ \\
\hline Year 8 or equivalent & $3(5)$ \\
\hline Year $9-11$ or equivalent & $13(24)$ \\
\hline \multicolumn{2}{|l|}{ Living situation $(n=56)$} \\
\hline Home (independent) & $47(84)$ \\
\hline Home (with additional care) & $7(12)$ \\
\hline Nursing Home & $2(4)$ \\
\hline \multicolumn{2}{|l|}{ Glasgow Outcome Score-Extended } \\
\hline Is the person able to obey simple commands? Yes & $56(100)$ \\
\hline $\begin{array}{l}\text { Is the assistance of another person at home essential } \\
\text { every day for ADLs? Yes }\end{array}$ & $9(16)$ \\
\hline Was this necessary prior to the OHCA? Yes & $2(3.5)$ \\
\hline Are they able to shop without assistance? Yes & $47(84)$ \\
\hline Are they able to travel locally without assistance? Yes & $47(84)$ \\
\hline Are they currently able to work to previous capacity? Yes & $23(41)$ \\
\hline $\begin{array}{l}\text { Are they able to resume regular social and leisure activities } \\
\text { outside? Yes }\end{array}$ & $31(55)$ \\
\hline $\begin{array}{l}\text { Are there psychological problems resulting in family or friendship } \\
\text { disruptions? Yes }\end{array}$ & $0(0)$ \\
\hline $\begin{array}{l}\text { Are there any other current problems due to OHCA affecting } \\
\text { daily life? Yes }\end{array}$ & $6(11)$ \\
\hline
\end{tabular}

Table 2 Continued

\begin{tabular}{lc}
\hline & $\mathbf{N}(\%)$ \\
\hline EQ-5D ( $\mathrm{n}=56)$ & \\
Mobility & \\
$\quad$ No problems & $42(75)$ \\
Some problems & $11(19.6)$ \\
Confined to bed & $3(5.3)$ \\
Personal care & \\
$\quad$ No problems & $42(75)$ \\
Some problems & $11(19.6)$ \\
Unable to wash or dress yourself & $3(5.4)$ \\
Usual activities & \\
$\quad$ No problems performing usual activities & $37(66)$ \\
Some problems & $14(25)$ \\
Unable & $5(9)$ \\
Pain or discomfort & \\
No pain or discomfort & $40(71.4)$ \\
Moderate & $15(26.8)$ \\
Extreme & $0(0)$ \\
Unknown & $1(1.8)$ \\
Anxiety or depression & \\
Not anxious or depressed & $22(39.3)$ \\
Moderately anxious & $27(48.2)$ \\
Extremely anxious & $7(12.5)$ \\
\hline
\end{tabular}

OHCA, out-of-hospital cardiac arrest.

$(47 \%)$ to the same role. The majority of survivors $(84 \%)$ were living independently at the time of follow-up. The majority of patients reported having no problems with mobility (75\%), personal care $(75 \%)$ and pain or discomfort $(71 \%)$. However, a third of patients reported problems with usual activities, and $61 \%$ reported either moderate $(48 \%)$ or severe $(13 \%)$ anxiety post-OHCA.

The SF-12 was completed by 46 patients (table 3 ). The majority $(78 \%)$ of these patients described their health as good or better, with $52 \%$ answering that their physical health did not limit them in their physical activities. Only 28\% described having a lot of energy either 'a little of the time' or 'none of the time' and $41 \%$ described feeling down hearted and blue at least some of the time. In this study, the mean (SD) physical score was 46.5 (10) and the mean (SD) mental score was 38 (14.5) adjusted for Australian norms.

Table 4 details the multivariable logistic regression analysis examining factors associated with a good functional outcome. Ventricular fibrillation was shown to be associated with a good functional outcome in this group of survivors; however, the numbers in this study were small.

\section{DISCUSSION}

This is the first OHCA study to specifically focus on functional and quality of life outcomes in young adults who survive cardiac arrest. Given their potential for longer life expectancy, these patients would be expected to have additional healthcare costs, in particular if there are poor functional outcomes. This study shows that in fact most young adult patients who survive to leave hospital have a good outcome with $96 \%$ living at home at the time of follow-up and $84 \%$ living independently.

Comparing with other studies of older age groups, a prospective substudy of the Ontario Pre-hospital Advanced Life Support Study interviewed 305 survivors of OHCA at 12 months for CPC Score and Health Utilities Index score. ${ }^{8}$ The mean age of survivors was 63.9 years; $88 \%$ had a CPC score of $1,8 \%$ a CPC score of 2 and $4 \%$ a CPC of 3 . The median (IOR) for health 
Table 3 Short Form (SF) 12 results (46 patients completed this questionnaire)

\begin{tabular}{|c|c|c|}
\hline SF 12 questions & Rating & $\mathbf{N}(\%)$ \\
\hline \multirow[t]{5}{*}{ Would you say your health is } & Excellent & $7(15)$ \\
\hline & Very Good & $12(26)$ \\
\hline & Good & $17(37)$ \\
\hline & Fair & $4(9)$ \\
\hline & Poor & $6(13)$ \\
\hline \multirow{3}{*}{$\begin{array}{l}\text { Does your physical health limit you } \\
\text { in moderate activities, for example, } \\
\text { moving a table, vacuuming, playing golf }\end{array}$} & Not at all & $24(52)$ \\
\hline & Limited a little & $11(24)$ \\
\hline & Limited a lot & $11(24)$ \\
\hline \multirow{3}{*}{$\begin{array}{l}\text { Does your physical health now limit } \\
\text { you in climbing stairs }\end{array}$} & Not at all & $24(52)$ \\
\hline & Limited a little & $15(33)$ \\
\hline & Limited a lot & $7(15)$ \\
\hline \multirow{2}{*}{$\begin{array}{l}\text { In the past } 4 \text { weeks, have you } \\
\text { accomplished less than you would like } \\
\text { as a result of your physical health }\end{array}$} & No & $26(56)$ \\
\hline & Yes & $20(43)$ \\
\hline \multirow{2}{*}{$\begin{array}{l}\text { During the past } 4 \text { weeks were you limited } \\
\text { in the kind of work or other activities you } \\
\text { performed due to your physical health }\end{array}$} & No & $26(56)$ \\
\hline & Yes & $20(43)$ \\
\hline \multirow{2}{*}{$\begin{array}{l}\text { During the past } 4 \text { weeks, have you } \\
\text { accomplished less than you would like } \\
\text { as a result of any emotional problems }\end{array}$} & No & $26(56)$ \\
\hline & Yes & $20(43)$ \\
\hline \multirow{2}{*}{$\begin{array}{l}\text { During the past } 4 \text { weeks, have you not } \\
\text { worked or performed activities as } \\
\text { carefully as usual as a result of any } \\
\text { emotional problems }\end{array}$} & No & $31(67)$ \\
\hline & Yes & $15(33)$ \\
\hline \multirow{5}{*}{$\begin{array}{l}\text { During the past week, how much did } \\
\text { pain interfere with your normal work }\end{array}$} & Not at all & $34(74)$ \\
\hline & A little bit & $7(15)$ \\
\hline & Moderately & $4(9)$ \\
\hline & Quite a bit & $0(0)$ \\
\hline & Extremely & $1(2)$ \\
\hline \multirow{6}{*}{$\begin{array}{l}\text { During the past week have you felt } \\
\text { peaceful and calm }\end{array}$} & All of the time & $8(17)$ \\
\hline & Most of the time & $20(43)$ \\
\hline & A good bit of the time & $3(6)$ \\
\hline & Some of the time & $8(17)$ \\
\hline & A little of the time & $4(9)$ \\
\hline & None of the time & $3(6)$ \\
\hline \multirow{6}{*}{$\begin{array}{l}\text { During the past week have you had } \\
\text { a lot of energy }\end{array}$} & All of the time & $5(11)$ \\
\hline & Most of the time & $18(39)$ \\
\hline & A good bit of the time & $4(9)$ \\
\hline & Some of the time & $6(13)$ \\
\hline & A little of the time & $9(20)$ \\
\hline & None of the time & $4(9)$ \\
\hline \multirow{6}{*}{$\begin{array}{l}\text { During the past week have you } \\
\text { felt down hearted and blue }\end{array}$} & All of the time & $2(4)$ \\
\hline & Most of the time & $5(11)$ \\
\hline & A good bit of the time & $3(6)$ \\
\hline & Some of the time & $9(20)$ \\
\hline & A little of the time & $14(30)$ \\
\hline & None of the time & $13(28)$ \\
\hline \multirow{5}{*}{$\begin{array}{l}\text { During the past week how much of the } \\
\text { time has your physical health or emotional } \\
\text { problems interfered with your social } \\
\text { activities }\end{array}$} & All of the time & $1(2)$ \\
\hline & Most of the time & $7(15)$ \\
\hline & Some of the time & $11(24)$ \\
\hline & A little of the time & $4(9)$ \\
\hline & None of the time & $23(50)$ \\
\hline
\end{tabular}

utilities index was $0.84(0.61-0.97)$. Therefore, most patients with cardiac arrest who survived to hospital discharge had a good quality of life and functional status.

In this study, the mean (SD) physical score was 45.6 (9.45) and the mean (SD) mental score was 38 (14.5) adjusted for Australian norms. An SF-12 Physical Component Summary Score or Mental Component Summary Score $\leq 40$ represents moderate to severe disability.

There are multiple tools used to measure quality of life and functional outcomes after survival from $\mathrm{OHCA}^{5}$; one systematic
Table 4 ORs for the association between selected Utstein elements and good survival outcome defined as CPC $1-2$ or GOS-E $\geq 5(n=93)^{*}$ Characteristics of OHCA Adjusted OR (95\% Cl)

Ventricular fibrillation

6.5 (1.5 to 27.8$)$

Witnessed Arrest

$2.5(0.7$ to 9.5$)$

Bystander CPR

$0.4(0.1$ to 1.8$)$

Male

$1.9(0.5$ to 8.1$)$

Home OHCA

$1.8(0.5$ to 6.8$)$

EMS response time

$1.0(0.9$ to 1.2$)$

*ORs calculated using multivariable logistic regression using all variables listed. CPC, Cerebral Performance Category; EMS, emergency medical services; GOS-E, Glasgow Outcome Scale-Extended; OHCA, out-of-hospital cardiac arrest; CPR, cardiopulmonary resuscitation.

review found over 50 functional and quality of life outcome measurement tools highlighting the lack of consensus in this area. ${ }^{5}$ Factors affecting use of any assessment tool include the tool's proven validity, the availability of national norms data for that tool, whether timing of follow-up using the tool introduces variability and whether precardiac arrest health is accounted or adjusted for in postcardiac arrest outcomes assessment. Also relevant is the cost of the tool including training of interviewers, the time required to administer the tool as well as the license fee. Elliott et $a l^{5}$ in their systematic review of quality of life and other patient-centred outcomes after cardiac arrest survival make specific reference to the Health Utilities Index 3 as being reliable, reproducible and valid in a variety of populations as well as to the advantages of the SF 36 and the EQ-5D. They recommend urgent attention be given to developing a consensus on methods to measure OHCA outcomes in the following areas: health-related quality of life, affective and post-traumatic stress symptoms, cognitive dysfunction and health economics. ${ }^{5}$ They highlight the need for standardisation of the follow-up and assessment intervals and the need for an appropriate comparator group to contextualise the findings.

The CPC is notable for its simplicity and ease of use being ascertainable from the hospital record but it is a blunt instrument and does not determine major issues such as whether that patient was able to return to work or longer term outcomes. Accurate data are important in this area as it informs treatment decisions and prognostication. It is also important to measure the impact of changes in resuscitation algorithms, therapeutic hypothermia, interventional cardiology and antiarrhythmia interventions, the impact of which may not be captured by survival alone. ${ }^{30}$

\section{Limitations}

This study has a number of limitations. Memory disturbance in survivors of OHCA has been reported in $62 \%{ }^{31}$ in one study and $74 \%{ }^{32}$ in another. However, this is difficult to determine using a telephone interview. The Neurobehavioural Cognitive Status Examination $^{33}$ used in previous studies is not amenable to being performed by telephone, may take $45 \mathrm{~min}$ to perform at the bedside and has a license fee. None of the tools used in our study directly measure memory though some patients did mention it as an issue.

We were only able to complete telephone follow-up on 56 patients (53\%). Young adults are a difficult group to follow-up owing to their high likelihood of moving location, particularly given that the follow-up for this study ranged from 2.7 to 8.6 years. Drug overdose and attempted suicide are overrepresented in this patient group ${ }^{10}$ many of whom may be reluctant to discuss the incident later. In some instances, the contact details in the hospital chart were incomplete; this may be because accurate identification of unconscious OHCA 
patients at the point of entry to the hospital may be uncertain. Also, the SF-12 Health Survey is recommended for large group epidemiological studies $(>n=200)$ where information on the SF36 Health Survey Summary Scores is required; it cannot be answered by proxy. Nevertheless, because of our staff familiarity with this tool, and the ease of telephone administration, this tool was used notwithstanding the limitations of its use in a smaller study.

Because inhospital data were not collected, the impact of postadmission treatments was not measured in this study.

\section{CONCLUSIONS}

The majority of young adults who survive cardiac arrest have good functional and quality of life outcomes. While telephone follow-up is feasible in the young adult survivors of cardiac arrest, loss to follow-up is common. The major determinant of good long-term functional recovery was ventricular fibrillation as the initial cardiac rhythm.

Acknowledgements Marian Lodder, Vanessa Barnes and VACAR staff. Ambulance Victoria paramedics. Paul Jennings, Belinda Gabbe, Ann Sutherland, Ceridwyn Freeman, Department of Epidemiology and Preventive Medicine. Monash University.

Contributors All the authors were involved in the study design and editing of this paper. CD performed telephone follow-ups, hospital chart reviews and the first draft of manuscript.

Funding Dr C Deasy was supported by a Monash University overseas PhD student scholarship during this project.

Competing interests None.

Ethics approval Ethics approval was provided by the Monash University Human Research Ethics Committee.

Provenance and peer review Not commissioned; externally peer reviewed.

\section{REFERENCES}

1. Testa MA, Simonson DC. Assesment of quality-of-life outcomes. N Engl J Med 1996;334:835-40.

2. Guyatt GH, Naylor CD, Juniper $\mathrm{E}$, et al. Users' guides to the medical literature. XII. How to use articles about health-related quality of life. Evidence-Based Medicine Working Group. JAMA 1997;277:1232-7.

3. Pusswald G, Fertl E, Faltl M, et al. Neurological rehabilitation of severely disabled cardiac arrest survivors. Part II. Life situation of patients and families after treatment. Resuscitation 2000;47:241-8.

4. Herlitz J, Andersson E, Bang A, et al. Experiences from treatment of out-of-hospital cardiac arrest during 17 years in Goteborg. Eur Heart J 2000;21:1251-8.

5. Elliott VJ, Rodgers DL, Brett SJ. Systematic review of quality of life and other patient-centred outcomes after cardiac arrest survival. Resuscitation 2011;82:247-56.

6. Jennett B, Bond M. Assessment of outcome after severe brain damage. Lancet 1975:1:480-4.

7. Cummins RO, Chamberlain DA, Abramson NS, et al. Recommended guidelines for uniform reporting of data from out-of-hospital cardiac arrest: the Utstein Style. A statement for health professionals from a task force of the American heart association, the European resuscitation Council, the heart and Stroke Foundation of Canada, and the Australian resuscitation Council. Circulation 1991;84:960-75.
8. Stiell IG, Nesbitt LP, Nichol G, et al. Comparison of the cerebral performance category score and the health utilities index for survivors of cardiac arrest. Ann Emerg Med 2009;53:241-8.

9. Zipes DP, Wellens HJ. Sudden cardiac death. Circulation 1998;98:2334-51.

10. Deasy C, Bray JE, Smith K, et al. Out-of-hospital cardiac arrests in young adults in Melbourne, Australia. Resuscitation 2011:82:830-4.

11. ABS. Australian Bureau of Statistics 2006 Census of population and Housing. Melbourne, Victoria. http://www.abs.gov.au/ (accessed 11 Oct 2011).

12. Smith KL, Peeters A, McNeil JJ. Results from the first 12 months of a fire firstresponder program in Australia. Resuscitation 2001;49:143-50.

13. Ambulance Victoria. Clinical Practice Guidelines. http://www.ambulance.vic.gov. au/Paramedics/Qualified-Paramedic-Training/Clinical-Practice-Guidelines.html

14. Australian Resuscitation Council. Guidelines. http://www.resus.org.au

15. Fridman $\mathbf{M}$, Barnes $\mathrm{V}$, Whyman $\mathrm{A}$, et al. A model of survival following pre-hospital cardiac arrest based on the Victorian Ambulance Cardiac Arrest Register. Resuscitation 2007;75:311-22.

16. Gabbe BJ, Simpson PM, Hart MJ, et al. Population-based capture of long-term functional and quality of life outcomes after major trauma: the experiences of the Victorian State Trauma Registry. J Trauma 2010;69:532-6; discussion 536.

17. Teasdale GM, Pettigrew LE, Wilson JT, et al. Analyzing outcome of treatment of severe head injury: a review and update on advancing the use of the Glasgow Outcome Scale. J Neurotrauma 1998;15:587-97.

18. Wilson JT, Pettigrew LE, Teasdale GM. Structured interviews for the Glasgow outcome scale and the extended Glasgow outcome scale: guidelines for their use. J Neurotrauma 1998;15:573-85.

19. Stark RG, Reitmeir $P$, Leidl R, et al. Validity, reliability, and responsiveness of the EQ-5D in inflammatory bowel disease in Germany. Inflamm Bowel Dis 2011:106:42-51

20. Oster C, Willebrand M, Dyster-Aas J, et al. Validation of the EQ-5D questionnaire in burn injured adults. Burns 2009;35:723-32.

21. Bosch JL, Hunink MG. Comparison of the health utilities index Mark 3 (HUI3) and the EuroQol EQ-5D in patients treated for intermittent claudication. Qual Life Res 2000:9:591-601.

22. Cherepanov D, Palta M, Fryback DG. Underlying dimensions of the five healthrelated quality-of-life measures used in utility assessment: evidence from the National Health Measurement Study. Med Care 2010;48:718-25.

23. Malmivaara K, Hernesniemi J, Salmenpera R, et al. Survival and outcome of neurosurgical patients requiring ventilatory support after intensive care unit stay. Neurosurgery 2009:65:530-7; discussion 537-8.

24. Pavoni V, Gianesello L, Paparella L, et al. Outcome predictors and quality of life of severe burn patients admitted to intensive care unit. Scand J Trauma Resusc Emerg Med 2010;18:24

25. Granja C, Cabral G, Pinto AT, et al. Quality of life 6-months after cardiac arrest Resuscitation 2002;55:37-44.

26. Kuilman M, Bleeker JK, Hartman JA, et al. Long-term survival after out-of-hospital cardiac arrest: an 8-year follow-up. Resuscitation 1999;41:25-31.

27. Graf J, Muhlhoff C, Doig GS, et al. Health care costs, long-term survival, and quality of life following intensive care unit admission after cardiac arrest. Crit Care 2008;12 R92.

28. Horsted TI, Rasmussen LS, Meyhoff CS, et al. Long-term prognosis after out-ofhospital cardiac arrest. Resuscitation 2007;72:214-18.

29. Wachelder EM, Moulaert VR, van Heugten C, et al. Life after survival: long-term daily functioning and quality of life after an out-of-hospital cardiac arrest. Resuscitation 2009; 80:517-22

30. Deasy C, Bray JE, Smith K, et al. Cardiac arrest outcomes before and after the 2005 resuscitation guidelines implementation: evidence of improvement? Resuscitation 2011;82:984-8.

31. Cronberg $\mathbf{T}$, Lilja G, Rundgren $\mathrm{M}$, et al. Long-term neurological outcome after cardiac arrest and therapeutic hypothermia. Resuscitation 2009;80:1119-23.

32. O'Reilly SM, Grubb NR, O'Carroll RE. In-hospital cardiac arrest leads to chronic memory impairment. Resuscitation 2003:58:73-9.

33. Kiernan RJ, Mueller J, Langston JW, et al. The Neurobehavioral Cognitive Status Examination: a brief but quantitative approach to cognitive assessment. Ann Intern Med 1987:107:481-5 